\title{
Hydrological characterisation of Ria de Aveiro, Portugal, in early summer
}

\author{
João Miguel DIAS ${ }^{\mathrm{a}^{*}}$, José Fortes LOPES ${ }^{\text {a }}$, Ivan DEKEYSER ${ }^{\text {b }}$ \\ ${ }^{a}$ CZCM, Departamento de Física, Universidade de Aveiro, 3810-193 Aveiro, Portugal \\ ${ }^{\mathrm{b}} \mathrm{COM}$, université de la Méditerranée (Aix-Marseille II) 13288 Marseille cedex 9, France
}

(Received 27 June 1998, revised 26 February 1999, accepted 25 May 1999)

\begin{abstract}
The hydrological features of Ria de Aveiro, a coastal lagoon on the northwest Atlantic coast of Portugal, were investigated in two sampling surveys carried out between $3 / 6$ and 24/6/97 and between $29 / 6$ and 7/7/97, respectively. There was a significant freshwater inflow into the lagoon during the first survey, especially in the first days, due to the recent rainfalls. Records concerning water level, salinity, temperature and current velocity were performed at several stations located along the four main channels of the lagoon. The type of tide at the mouth was determined and was observed that astronomical tide is the main forcing agent driving water circulation in Ria de Aveiro. The tide at the mouth is semidiurnal and the tidal wave propagation in the lagoon has the characteristics of a damped progressive wave. Typical estuarine longitudinal salinity and temperature gradients connected with the distance to the mouth were identified, whereas vertical and transverse gradients were found unimportant, except in the frontal zone between oceanic and fresh water masses. According to the results, even though Ria de Aveiro should be considered as vertically homogeneous, some channels may reveal characteristics of a partially mixed estuary, depending on the freshwater input. (C) 1999 Ifremer / CNRS / IRD / Éditions scientifiques et médicales Elsevier SAS
\end{abstract}

\section{water level / salinity / temperature / current velocity / Ria de Aveiro}

Résumé - Caractérisation hydrologique de la Ria de Aveiro, Portugal, au début de l'été. Les caractéristiques hydrologiques de la Ria de Aveiro, lagune côtière située au nord-ouest du Portugal, ont été étudiées au cours de deux campagnes effectuées entre le 3 et le 24 juin 1997 et entre le 29 juin et le 7 juillet 1997. Ces périodes suivent d'importants apports d'eau douce dus à des pluies survenues au début de la première campagne. Le niveau de l'eau, la salinité, la température ainsi que l'intensité et la direction du courant ont été enregistrés en plusieurs stations situées le long des quatre branches principales de la Ria de Aveiro. Les caractéristiques de la marée à l'embouchure de la Ria ont été mises en évidence. La circulation à l'intérieur de la lagune est principalement forcée par la marée astronomique de type semi-diurne. Les ondes de marée résultantes ont la caractéristique d'ondes progressives amorties. À l'exception de la zone frontale entre les eaux océaniques et douces, où il existe une certaine stratification verticale et transversale, les gradients de salinité et de température sont typiquement longitudinaux. Bien que la Ria d'Aveiro puisse être considérée comme étant verticalement homogène, certaines branches ont les caractéristiques d'un estuaire partiellement mélangé, variables avec les apports d'eau douce. (C) 1999 Ifremer / CNRS / IRD / Éditions scientifiques et médicales Elsevier SAS

\section{surélévation / salinité / température / vitesse du courant / Ria de Aveiro}

\section{INTRODUCTION}

Ria de Aveiro is a very important area on the Portuguese coast. It provides natural conditions for harbour, naviga- tion and recreation facilities and it is also a place of discharge of domestic and industrial wastes. It offers good conditions for agricultural development along its borders and for the setting up of a large number of small and medium industries.

\footnotetext{
* Correspondence and reprints: jdias@ fis.ua.pt
} 
More than 300000 people live around the lagoon and its channels; this concentration in a small area brings up sev eral environmental and pollution problems. The study of these kinds of problems must be based upon an understanding of the biological, chemical and geological processes, which are highly dependent on the lagoon's hydrodynamics, and implies the existence of an extensive data set concerning water quality and physical parameters.

Despite its economical, social and environmental importance, no previous hydrological measurements covering the whole lagoon have been made. The most comprehensive study concerns biological and environmental research; Moreira et al. [17], Queiroga et al. [22] and Silva [24] performed some localised measurements of water temperature, salinity and currents.

The aim of this work is to study tide and current properties as well as to characterize the horizontal and vertical variations of salinity and temperature in Ria de Aveiro during an early summer period. To achieve these goals two different observational surveys have been carried out. In the present paper water level, salinity, temperature and current measured in several different places covering the entire lagoon are presented.

\section{STUDY AREA}

Ria de Aveiro is a shallow coastal lagoon on the northwest Atlantic coast of Portugal ( $40^{\circ} 38^{\prime} \mathrm{N}, 8^{\circ} 44^{\prime} \mathrm{W}$ ), separated from the sea by a sand bar. It has a very irregular and complex geometry (figure 1 ), characterized by narrow channcls and by the existence of significant intertidal zones, namely mud flats and salt marshes. It is connected with the Atlantic through an artificial channel and exchanges the most part of its water with the ocean by tidal input across this narrow entrance, $1.3 \mathrm{~km}$ long, $350 \mathrm{~m}$ wide and $20 \mathrm{~m}$ deep. The lagoon has a maximum width and length of 10 and $45 \mathrm{~km}$, respectively, and in a spring tide covers an area of $83 \mathrm{~km}^{2}$ at high tide, which is reduced to $66 \mathrm{~km}^{2}$ at low tide. The average depth of the lagoon is about $1 \mathrm{~m}$, except in navigation channels where dredging operations are frequently carried out.

Morphologically, Ria de Aveiro has the characteristics of a typical bar-built estuary [21], having experienced incision during an ice age and subsequent flooding, attenuated at present due to recent sedimentation with material from the coastal erosion entering the lagoon mouth from the rivers.

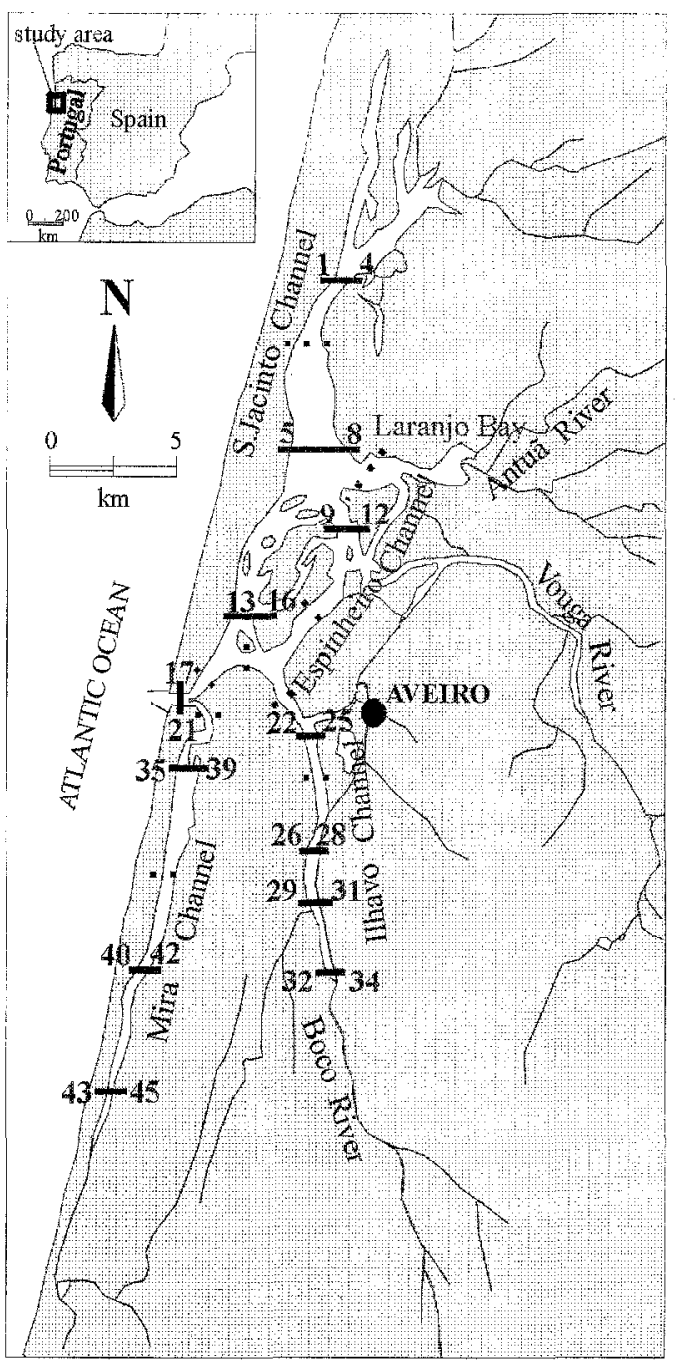

Figure 1. Geographic map of Ria de Aveiro. The stations are located on the solid lines; the numbers over the lines represent the first and the last stations placed along that line.

The lagoon has four main branches radiating from the sea entrance (figure 1): Mira, S. Jacinto, Ilhavo and Espinheiro channels. The Mira channel is an elongated shallow arm, $20 \mathrm{~km}$ in length, which receives continuous freshwater input at its far end from a small system of ponds and rivers. According to Moreira et al. [17] this channel behaves like a tidally and seasonally poikilohaline estuary with a salinity range from 35.1 to 0.0 . Water temperature $\left(8.5-24.7^{\circ} \mathrm{C}\right)$ decreases along the channel towards its far extremity during the cold season; an inverse and more pronounced trend was observed during the hot season. The S. Jacinto channel is about $29 \mathrm{~km}$ long and is the most important channel in terms of average width and 
length. Ilhavo channel is the narrower and shorter of the main channels, wilh a length of $15 \mathrm{~km}$. Discharging into this channel is a small river, the Boco, of little importance in terms of freshwater input. Finally, Espinhciro is a short channel of about $17 \mathrm{~km}$ in length which has a complex network of small dead arms. Two rivers, the Vouga and Antuã, discharging into the east side of the lagoon constitute a major source of fresh water. The average flow for the Vouga river and Antuã river is around $29 \mathrm{~m}^{3} \mathrm{~s}^{-1}$ and $2 \mathrm{~m}^{3} \mathrm{~s}^{-1}$, respectively.

The total mean river discharge during a tidal cycle into the lagoon is about $1.8 \times 10^{6} \mathrm{~m}^{3}$ [17] while the tidal prism at the mouth in a spring tide with a tidal range of $2.48 \mathrm{~m}$ is about $70 \times 10^{6} \mathrm{~m}^{3}$ [27]. The tidal prism in each one of the main channels relative to its value at the mouth is about $38 \%$ for the S. Jacinto channel, $26 \%$ for the Espinheiro channel, $10 \%$ for the Mira channel and $8 \%$ for the Ilhavo channel [24].

The tides at the mouth of the lagoon are predominantly semidiunal, with a mean tidal range of about $2.0 \mathrm{~m}$. The minimum tidal range is $0.6 \mathrm{~m}$ (neap tides), and the maximum tidal range is about $3.2 \mathrm{~m}$ (spring tides), corresponding to a maximum and a minimum water level of 3.5 and $0.3 \mathrm{~m}$, respectively. According to these values, Ria de Aveiro is a mesotidal lagoon [4]. Tidal currents inside the lagoon have a maximum speed of about $1.0 \mathrm{~m} \mathrm{~s}^{-1}$ [27].

\section{MATERIALS AND METHODS}

\subsection{Sampling strategy}

The data presented in this study were collected during two different surveys (figure 2). The sampling strategy of the first survey (table $I$ ) includes twelve measurement

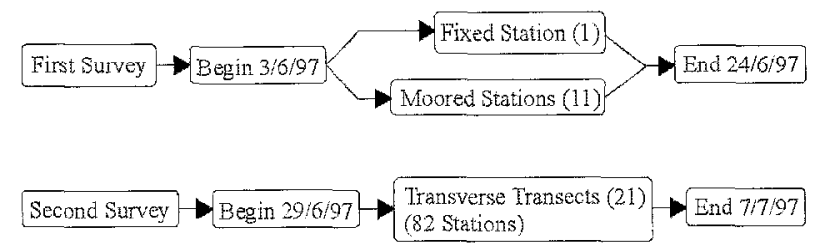

Figure 2. Sampling schedule and strategy.

stations, each one located on one of the twelve welldefined transverse transects (solid lines on figure 1), distributed over the main channels of the lagoon. Sampling was conducted for 22 days, between $3 / 6$ and 24/6/97. At a fixed station near the mouth measurements were carried out throughout the period referred to, in order to obtain data which can be compared with the measurements at the moored stations. At each moored station, measurements were accomplished during a single $13 \mathrm{~h}$ period, in order to cover the semidiurnal tidal cycle. In the second sampling, performed between 29/6 and 7/7/97, 21 transverse transects (nine new transects represented by the dotted lines in figure l) were defined, each one with three to five sampling stations, depending on the width of the channel. A total of 82 stations were used to determine single vertical profiles of salinity and temperature in the lagoon.

\subsection{Fixed station}

Measurements of water level, salinity and temperature at a fixed station located near the mouth of the lagoon were made. A mini-STD Markdan Ocean SD200, fixed $45 \mathrm{~cm}$ above the bottom (station 21, figure 1), was used. Water pressure, conductivity and temperature were measured and data were stored every five minutes. Salinity was computed through the composite equation approved by Unesco [26].

Table 1. Station characteristics and data acquisition procedures for the first survey.

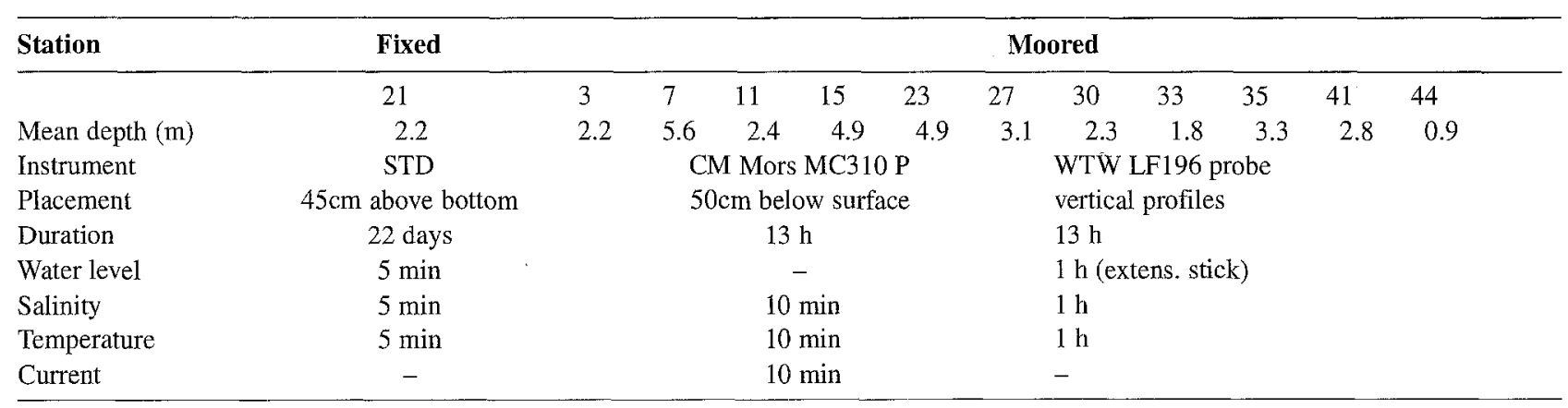




\subsection{Moored stations}

Eleven moored stations were distributed within the main channels of the lagoon (figure 1). They were located in the deepest zone of each transect in order to allow measurements in periods of low water. At these stations, time series of water level, salinity, temperature and current velocity were measured, as well as vertical profiles of salinity and temperature [9].

The water height was measured every hour using a rough system consisting of an extensible graduated stick. Salinity, temperature and current direction and velocity were measured $50 \mathrm{~cm}$ below the water surface at $10 \mathrm{~min}$ intervals using a Mors MC310P vector averaging current meter with a conductivity sensor type Aanderaa and a temperature sensor type Cupro. This instrument has a Balanced Savonius rotor to measure the current speed in a linear range from $0-2.5 \mathrm{~ms}^{-1}$ with an accuracy of $2 \mathrm{~cm} \mathrm{~s}^{-1}$ and a starting velocity of $2.5 \mathrm{~cm} \mathrm{~s}^{-1}$. The current direction is measured using a Fluxgate compass and a low inertia vane with a range from $0-360^{\circ}$ with a resolution of $1.4^{\circ}$.

\subsection{Transverse transects}

Vertical profiles of salinity and temperature were obtained in all the stations along the transverse transects represented in figure 1 deploying the STD referred to above. All stations were sampled one hour after the local predicted high tide. The profiles obtained for the 45 stations shown in figure 1 (solid lines) were plotted in order to observe the vertical and lateral salinity and temperature distributions. The total of 82 profiles were used to interpolate the thermal and saline structures in the lagoon.

\subsection{Meteorological conditions}

Before the first survey and during its first week, strong and persistent precipitation occurred in the study area (figure 3). This rainfall is unusually high in this zone for the summer season (mean total monthly values are lower than $50 \mathrm{~mm}$ [1]). After this period the sky was always clear and temperatures were high, as expected for this season (figure 3); the climatological mean daily values are about $17^{\circ} \mathrm{C}$ [1]. The wind intensity was normal for the season, where the mean monthly values are of about $15 \mathrm{~km} \mathrm{~h}^{-1}$ [7]. No measurements of freshwater input into

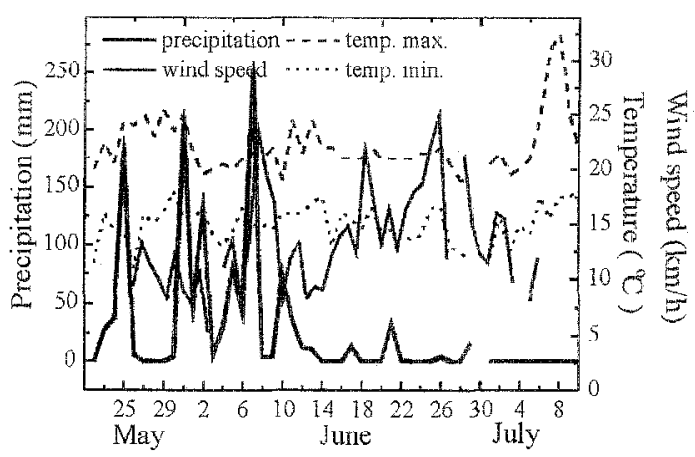

Figure 3. Precipitation, wind intensity and maximum and minimum air temperature in Aveiro meteorological station during the surveys.

the lagoon through the existent rivers were carried out, but significant inputs were expected, especially in the first survey period.

\section{RESULTS}

\subsection{Water mass characteristics at the mouth}

The water level, salinity and temperature observations measured at the mouth of the lagoon were filtered in order to cut off the high frequencies. The filter used [13] has a cut off frequency of $3.3 \times 10^{-4} \mathrm{~Hz}$. Time series of the filtered values of the referred data are plotted in figure 4 . The tide was semidiurnal with a diurnal inequality. A minimum water level of $0.47 \mathrm{~m}$ and a maximum water level of $3.34 \mathrm{~m}$ was observed in the spring tide. Salinity also had a strong semidiurnal component, with a maximum valuc of 36.35 characteristic of occan watcr and a minimum value of 24.18 . The temperature evolution is not so regular, especially in the first ten days of sampling. The maximum and minimum values were, respectively, $22.05^{\circ} \mathrm{C}$ and $17.44^{\circ} \mathrm{C}$. The periodicity of the salinity and temperature time series is dependent on the water level evolution; the higher salinity values and the lower temperature values were observed at high water, while the lower and higher salinity and temperature values, respectively, were measured at low water.

Moreira et al. [17] measured values of salinity and temperature in June 1986 at low water at a station close to the mouth (Mira channel) and found values of salinity and temperature of about 27 and $18{ }^{\circ} \mathrm{C}$, respectively. The values observed at low water in the first 15 days of the first survey are not typical for this summer season (lower salinity and higher temperature values than those referred 
a)

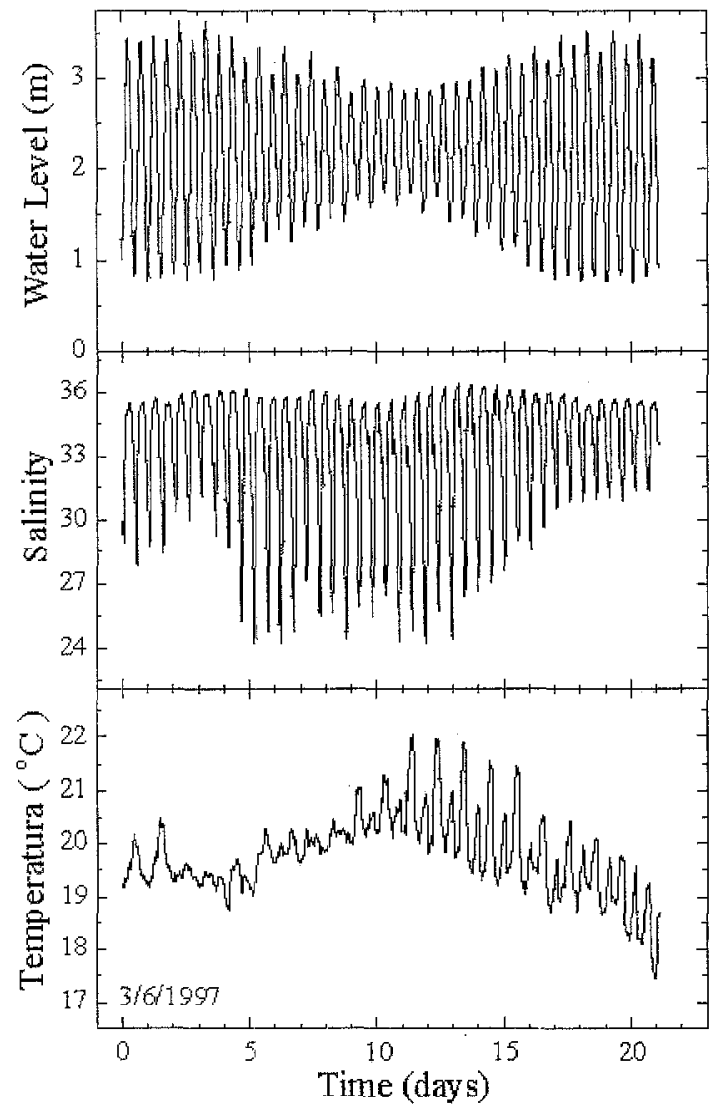

b)

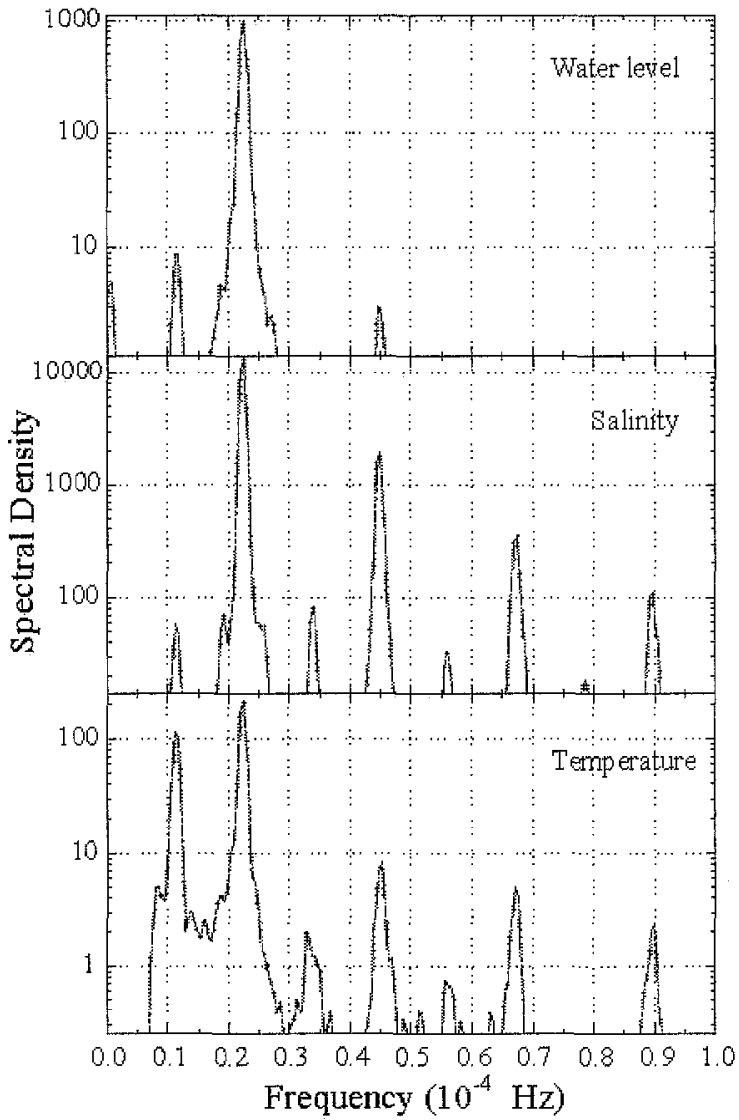

Figure 4. Time series (a) and computed spectral density (b) of the water height, salinity and temperature measured at the lagoon mouth.

for a dry season), and can be explained by an unusual freshwater input into the lagoon during this period due to the recent high rainfall.

The spectral densities computed for the water level, salinity and temperature time series analysed before are presented in figure 4 . The water level spectrum has a very high peak at the frequency of the semidiurnal constituents and an insignificant peak at the diurnal one. The salinity and temperature spectra also exhibit peaks at the same frequencies, as well as small peaks at the frequencies corresponding to the first harmonics of the semidiurnal constituents. The energy associated with the diurnal constituent in the temperature spectrum is very signifi- cant, revealing the importance of the solar radiation heating effect.

The water level data were also processed using a harmonic analysis package [12], and the results are presented in table II.

\subsection{Tidal propagation}

Figure 5 depicts the water heights measured simultaneously at each moored station and at the fixed station situated at the mouth of the lagoon. The analysis of these graphics reveals a tidal distortion and a reduction in the tidal amplitude. Table III presents the delays of the local

Table II. Harmonic analysis results for water height at the mouth of Ria de Aveiro.

\begin{tabular}{lcccccccc}
\hline Constituent & $\mathbf{O}_{\mathbf{1}}$ & $\mathbf{K}_{\mathbf{1}}$ & $\mathbf{P}_{\mathbf{1}}$ & $\mathbf{M}_{\mathbf{2}}$ & $\mathbf{S}_{\mathbf{2}}$ & $\mathbf{K}_{\mathbf{2}}$ & $\mathbf{M}_{4}$ & $\mathbf{M S}_{\mathbf{4}}$ \\
\hline Amplitude $(\mathrm{m})$ & 0.046 & 0.080 & 0.026 & 0.922 & 0.308 & 0.084 & 0.043 & 0.025 \\
Phase $\left({ }^{\circ}\right)$ & 329.5 & 72.1 & 79.2 & 106.0 & 143.9 & 166.3 & 293.6 & 340.2 \\
\hline
\end{tabular}


Table III. High water and low water delays relative to the mouth (H.W.D. and L.W.D., respectively) and difference between the amplitude at the mouth and at each moored station (D.A.M.S.).

\begin{tabular}{lccccccccccc}
\hline Station & $\mathbf{3}$ & $\mathbf{7}$ & $\mathbf{1 1}$ & $\mathbf{1 5}$ & $\mathbf{2 3}$ & $\mathbf{2 7}$ & $\mathbf{3 0}$ & $\mathbf{3 3}$ & $\mathbf{3 5}$ & $\mathbf{4 1}$ & $\mathbf{4 4}$ \\
\hline H.W.D. (min) & 140 & 70 & 40 & 15 & 45 & 80 & 125 & 135 & 10 & 50 & 115 \\
L.W.D. (min) & 245 & 80 & 65 & 15 & 85 & 120 & 155 & 160 & 60 & 215 & 355 \\
I.A.M.S. (m) & 1.34 & 0.35 & 0.18 & 0.09 & 0.27 & 0.55 & 0.78 & 0.81 & 0.08 & 1.09 & 1.73 \\
\hline
\end{tabular}

high and low water relative to the mouth, and the decrease in the tidal wave amplitude throughout the different stations and channels. With increasing distance from the mouth, a decrease of the local amplitudes can be observed relative to the amplitudes at the lagoon entrance and a delay of the high and low water, the latter being significantly higher in almost all the stations. This feature is

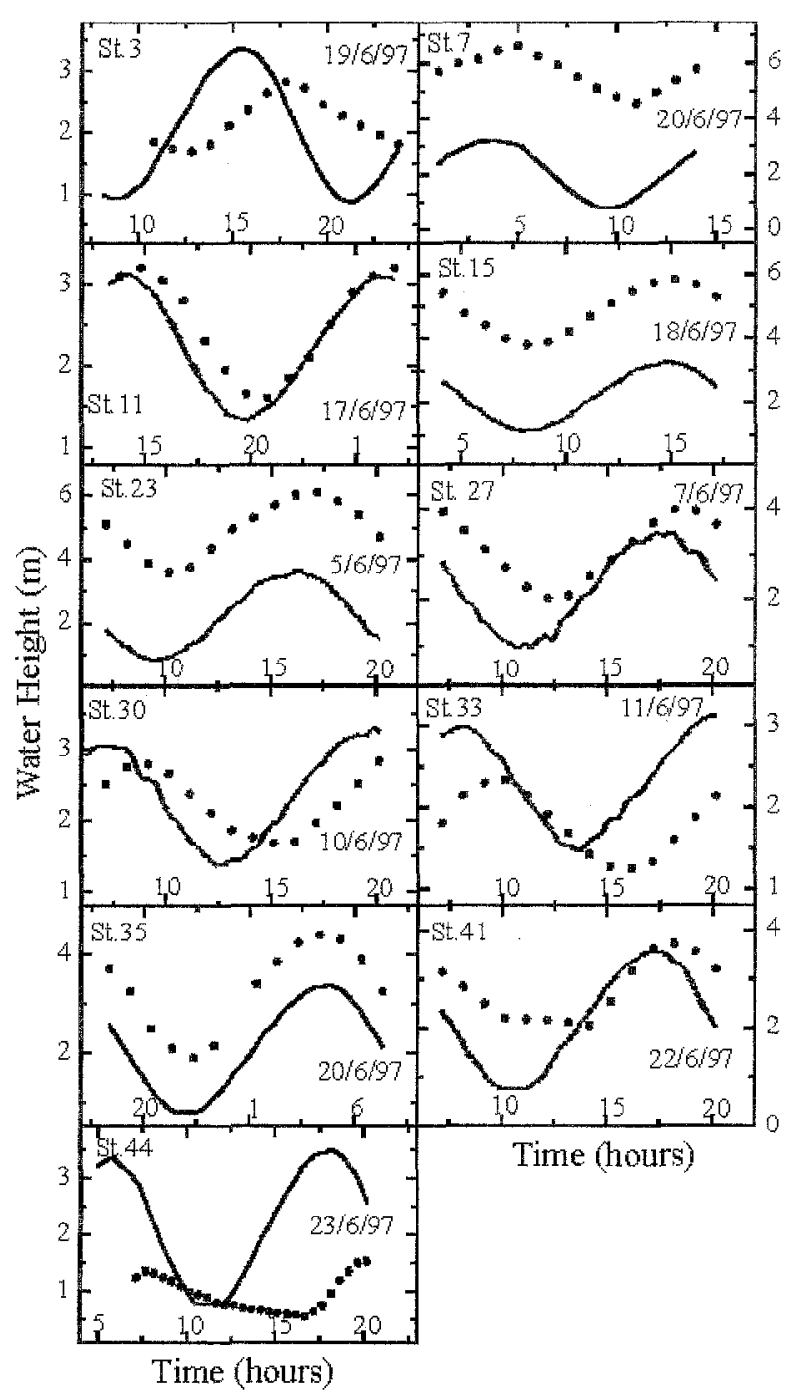

Figure 5. Concurrent water height at the mouth (solid line) and at each station (dotted line). particularly evident at the end of $\mathbf{S}$. Jacinto and Mira channels; there is a considerable tidal amplitude reduction between stations 7 and 3 (north channel) and stations 35,41 and 44 (south channel) in a short distance. The delays in high and low waters also increase significantly at these stations.

Figure 6 shows the water height evolution and the concurrent along and cross channel components of the flow velocity. At station 44 it was not possible to submerge the current meter due to the shallowness of the water. The values of measured current intensity at the Ilhavo channel stations $(23,27,30$ and 33$)$ are not representative of values that can occur at other points of this channel, because the measurements were performed from bridges situated at the narrowest zones of the channel, where the velocity is of course higher. The analysis of the velocity plots shows an important distortion of the tidal currents and reveals that there is no evident characteristic pattern for all the stations. From the results it can be observed that flow velocity and water height are out of phase, however, there is no common phase gap for all the stations. The ebb current at station 33 has a clear dent, in accordance with the fact that at this phase of the ebb the crosssectional area of the channel becomes smaller because a considerable intertidal area is not covered with water.

\subsection{Salinity and temperature evolution}

Salinity and temperature time evolutions at the stations of greater depth in each transverse section are presented in figure 7 , with the concurrent measurements at the mouth of the lagoon. By analysing the different curves it can be observed that the values measured in the stations close to the mouth $(7,11,15,23$ and 35$)$ have a nearly sinusoidal evolution, similar to that found at the mouth. Therefore salinity and temperature time evolutions are essentially dominated by tidal forcing in the central area of Ria de Aveiro.

The salinity time evolution in the other stations also reveals the influence of the tidal forcing, in spite of its reduced effect at the far end of the channels [8]. At 


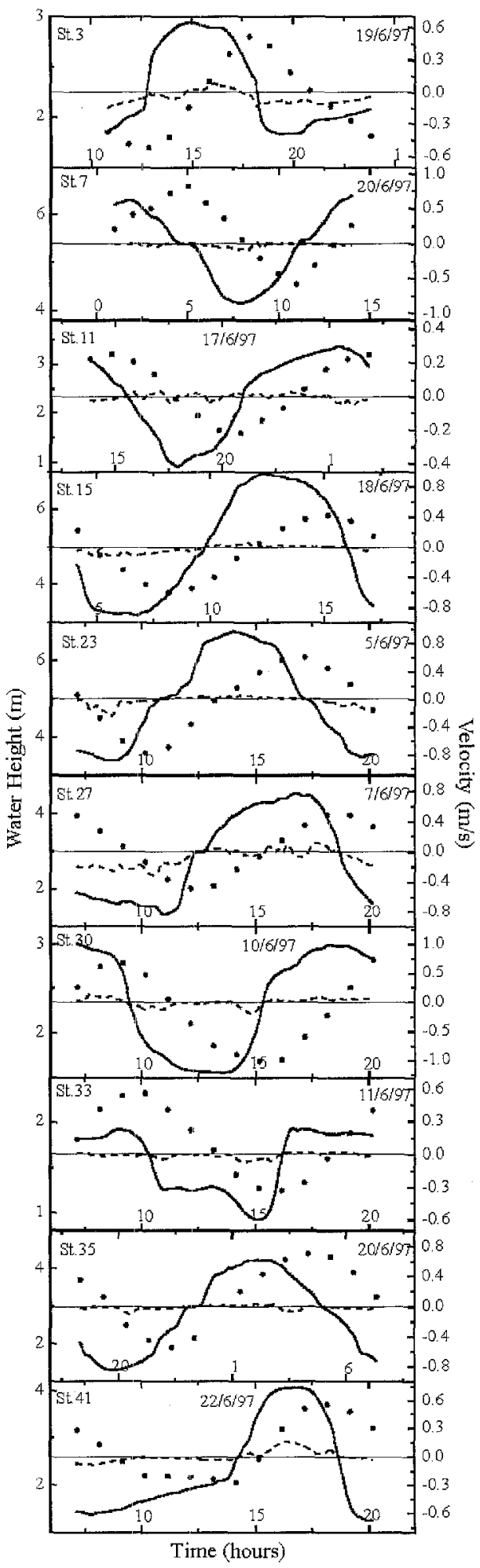

Figure 6. Concurrent water height (dotted line) and current components at each station (solid line - along channel component; dashed line - cross channel component ). Positive values of the along channel component correspond to the local flood.

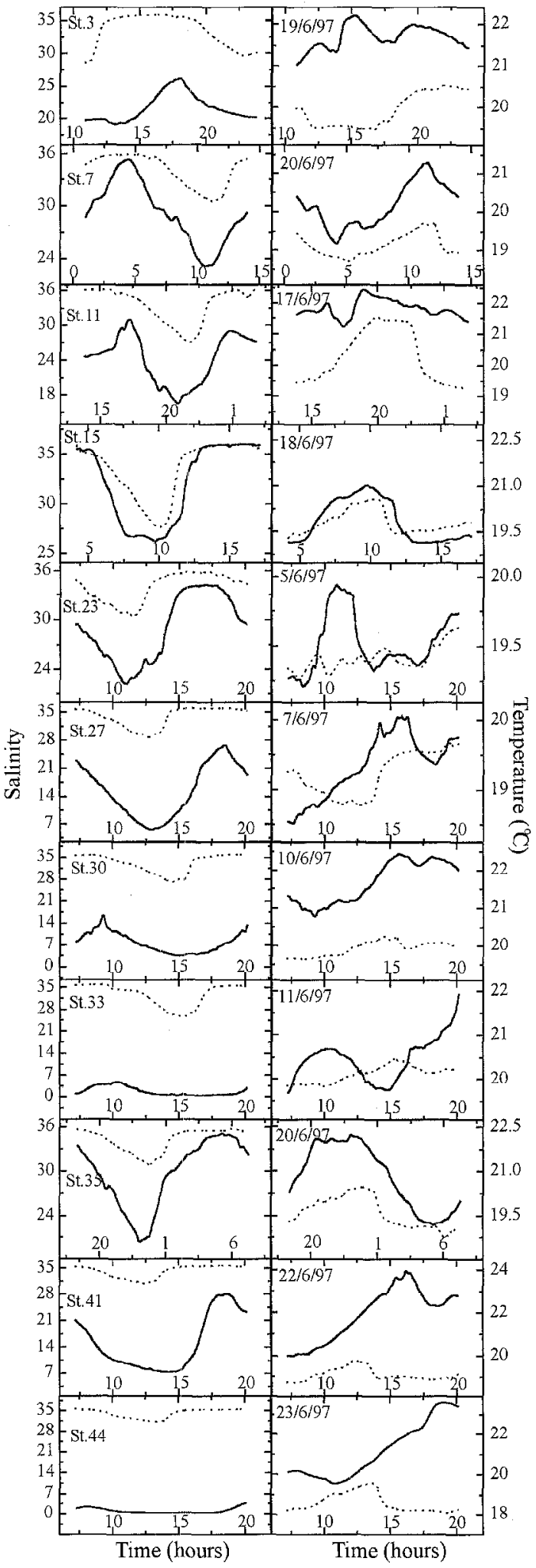

Figure 7. Concurrent salinity and temperature at the mouth (dashed line) and at each station (solid line). 


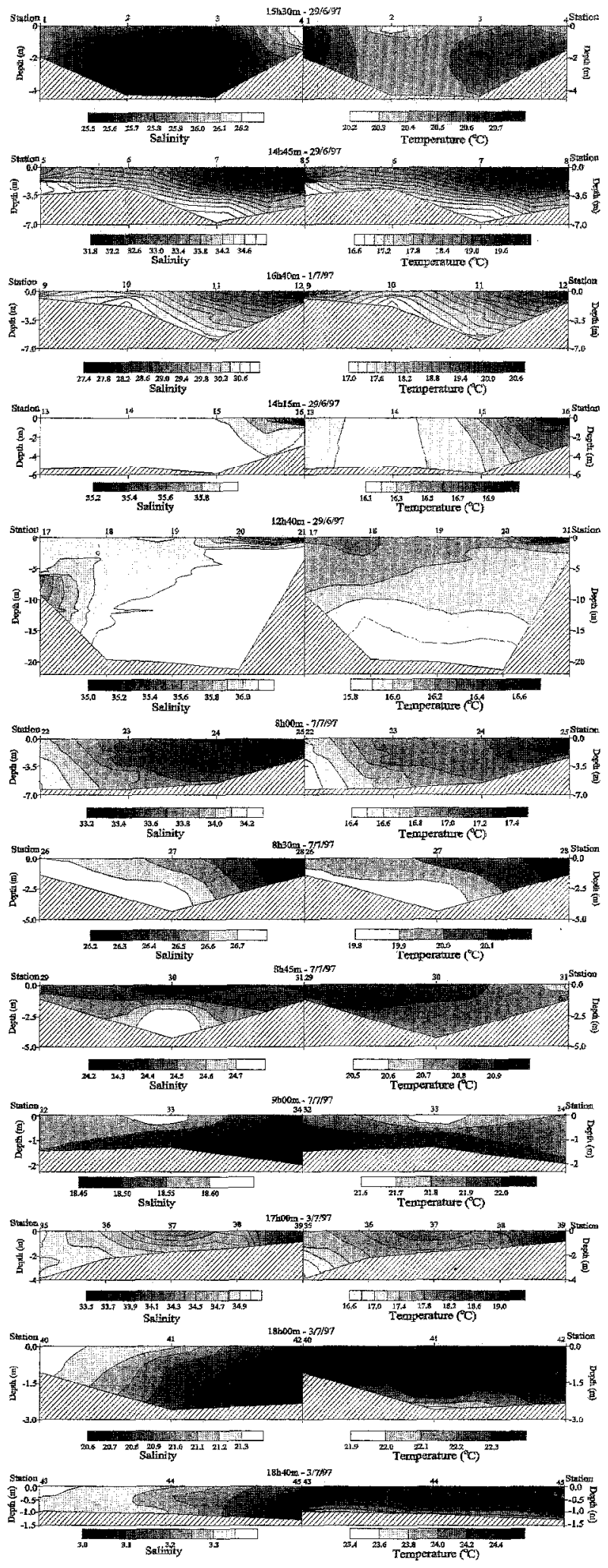

Figure 8. Salinity and temperature cross-sectional structure at each station. stations 33 and 44 the freshwater input decreases the salinity at low tide, resulting in a deformation of the sinusoidal pattern. The water temperature is also dependent on the insolation, which is considered uniform on the entire lagoon surface, with maximum values at about $13 \mathrm{~h}$ 30 (local time). At the far end stations of the main channels $(3,27,33,41$ and 44$)$ the highest temperature values are not correlated with the less salty water at low tide, but with the maximum intensity of the currents (figure 6), occurring after a relevant time of water surface warming.

High salinity amplitude observed at stations close to the mouth and even at the mouth station, as well as the low values at low tide observed at stations close to the rivers' direct influence $(7,11,33$ and 44$)$, reveal that there is a significant amount of freshwater inside the lagoon, due to the strong precipitation that occurred during the first days of the first survey.

Salinity and temperature vertical profiles evolution [9] are rather vertically uniform during the whole tidal cycle, except for all the stations situated at the Ilhavo channel (23-33), where the surface water has lower salinity and higher temperature than the bottom water. Considering that these measurements were made at the beginning of the first survey it is expected that the freshwater input from Boco river was significant relative to the tidal inflow at Ilhavo channel. The importance of this freshwater input can be confirmed observing the vertical structure obtained during the second survey (figure 8). In this last situation the freshwater input was very small and only at the two far sections of Ilhavo channel was observed a weak salinity and temperature vertical stratification.

\subsection{Salinity and temperature structure}

Figure 8 shows the salinity and temperature crosssectional structure for each transect represented by solid lines in figure 1, deduced from the vertical profiles measured one hour after the local high tide at each station. Even though two sections in S. Jacinto and Espinheiro channels (stations 5-8 and 9-12) present important vertical stratification, with higher values of temperature and lower values of salinity near the surface, vertical gradients are negligible in almost all the other stations. That particularity concerning these stations can be understood considering the fact that these two sections are under the direct influence of the Vouga and Antuã river inputs; the freshwater inflow from these rivers is still important two weeks after the rainfall. 
Even though the transversal salinity and temperature gradicnts are not very significant, there are some important features that must be pointed out. The structures found at the inlet of the lagoon (stations 17-21) reveal that the ebbing begins at the water surface, with cold and saline ocean water near the bottom. In the same section it is also possible to observe that at the surface and near the south margin there is a mass of water with higher temperature and lower salinity. This water mass comes from a domestic waste sewer located $300 \mathrm{~m}$ upstream of this section.

Figure 9 shows the salinity and temperature fields determined by interpolation using an Ordinary Kriging method [5]. A linear variogram isotropic model with the
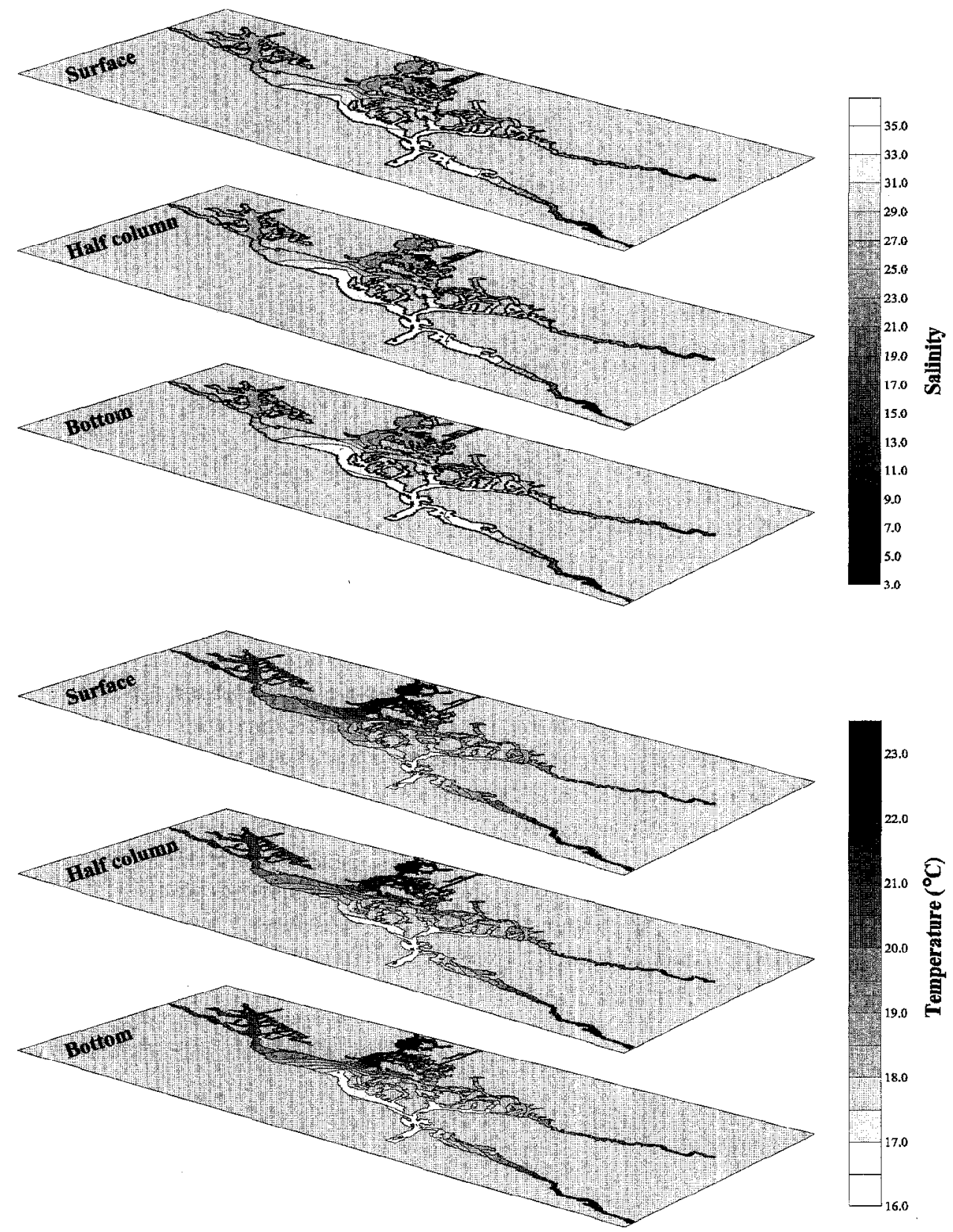

Figure 9. Salinity and temperature horizontal structure for Ria de Aveiro at three different levels. 
error variance equal zero was used. These fields were computed for three different depths $(0.5 \mathrm{~m}$ below the surface, mid-water column and close to the bottom) using measurements made one hour after high tide at the 82 different stations (solid and dotted lines in figure I). Longitudinal gradients of salinity and temperature are ohserved at each channel of the lagoon, with lower salinity and higher temperature values found at the far end of the channels. In the central zone of the lagoon the salinity and temperature values are close to those characteristic of ocean water. The lowest salinity and highest temperature values are observed at the end of Mira channel, on the eastern margin of Espinheiro channel and in Laranjo Bay. Therefore, the importance of the freshwater inputs in the establishment of the horizontal salinity and temperature structure in Ria de Aveiro is evident. The highest longitudinal gradients are found at Mira channel. At its far end the salinity value is close to that of the freshwater and the temperature is the highest measured in the lagoon.

The shape of the contour lines in the S. Jacinto channel reveals the importance of the freshwater inflow from Vouga and Antuã rivers in the hydrology of the Ria de Aveiro. The salinity and temperature structures are vertically very similar. However, in S. Jacinto channel the 35 isohaline and the $16^{\circ} \mathrm{C}$ isotherm are detected closer to the mouth at the water surface than at the bottom. The presence of a saline and thermal wedge near the mouth of the channel, with values typical of ocean water near the bottom identified at a greater distance from the mouth than at the surface, is therefore characteristic in the beginning of the cbb in this channel.

\section{DISCUSSION}

\subsection{Tidal dynamics}

The astronomical tide is the main forcing action driving water circulation in Ria de Aveiro. The first few diumal and semidiurnal constituents allow the general character of tides to be expressed. A tidal form number, $\mathrm{F}$, defined as [2]

$F=\frac{K_{1}+O_{1}}{M_{2}+S_{2}}$

where $K_{l}, O_{l}, M_{2}$, and $S_{2}$ are the amplitudes of the corresponding constituents, is used to determine the tidal type. Using the computed tidal harmonic constituents for the mouth of the lagoon (table In) this factor takes the value of 0.102 , classifying the tide as semidiurnal. $98 \%$ of the total energy is due to the semidiurnal constituents; the lunar principal, $M_{2}$, and the solar principal, $S_{2}$, are the main tidal constituents, with, respectively, $88 \%$ and $10 \%$ of the total energy. The diurnal, quadri-diurnal and long-period constiments have similar amplitudes and represent only a small part of the tidal energy.

As a result of non-linear characteristics of shallow water wave propagation, a particular harmonic constituent, such as the semidiurnal constituent $M_{2}$, can give rise to a series of higher harmonics, e.g. $M_{4}, M_{6}, M_{8}, \ldots$ with frequencies which are multiples of the basic frequency. These frequencies are present in the salinity and temperature time series recorded at the mouth of the lagoon (figure 4).

For the propagation of the tidal wave in a lagoon the shallow water theory is generally considered [19]. In this theory the velocity of the long waves, including tidal waves, is given by

$$
c=\sqrt{g h}
$$

and is independent of the free surface elevation, providing that the latter is small compared with the total water depth. In fact, a more accurate mathematical equation $[10,16]$ shows that the velocity of propagation is partly dependent upon the surface elevation, and is given by

$c=\sqrt{g(h+3 \zeta)}$

where $\zeta$ is the elevation of the surface above its undisturbed level. It is therefore reasonable to suppose that the velocity of a wave in Ria de Aveiro will be to some extent dependent upon the actual depth rather than on the mean depth. This dependence of $c$ on $\zeta$ explains why the crests of the tidal waves travel faster than the troughs, so that at particular points of the channels high waters appear to be accelerated, and low waters to be retarded, with the consequence that the tide rises more quickly than it falls. This shallow water effect is particularly evident for the last stations of S. Jacinto and Mira channels. The tidal delay between stations 7 and 3 and 35,41 and 44 is quite important (table III), due to the fact that the water elevation $\zeta$ is high compared with the depth $h$ of the water column.

Tide generates strong reversing currents in deep and narrow tidal channels (e.g. Gazi Bay [14]), but not in shallow intertidal zones. The strength and magnitude of tidal currents in Ria de Aveiro depend essentially on the crosssectional area and depth of the channels. The current speed is nearly $90^{\circ}$ out of phase with tidal elevation in every station and in the deeper stations the peak ebb and 
flood currents are symmetrical, implying that their duration and magnitude are near equal. In the shallow areas and at the end of the channels tidal asymmetry is more clearly evident, with stronger flood currents than ebb cur rents. This tidal asymmetry is partly attributed to the flow-retarding effects of salt marshes and mud flats and results from the superposition of the principal harmonic constituents with residual and higher harmonic (overtides) of the principal constituent.

The tidal amplitude and salinity variations are nearly $90^{\circ}$ out of phase with the current velocity in every station; this feature is a characteristic of standing waves [11]. However, the high and low water levels do not occur simultaneously at all points of the lagoon. The tidal wave in the lagoon is therefore neither a standing wave nor a progressive wave. In Ria de Aveiro the depth is very small and the water surface in most cases is large; the energy dissipation due to the bottom stress prevents the formation of standing waves, which result from the interference between the incident wave and the reflected waves inside the lagoon. Consequently, the general characteristics of the tidal wave in Ria de Aveiro are those of a damped progressive wave: during the propagation the amplitude decreases and the phase lag increases.

\subsection{Salinity and temperature evolution}

Variations in the level of salinity in semi-enclosed coastal waters are a result of evaporation, precipitation, ocean water influx and river discharge [6]. The most important factors causing strong salinity changes in Ria de Aveiro were found to be freshwater inflow and ocean inflow. Oceanic water is flushed out of the lagoon during the ebb period being replaced by brackish water from the far end of the channels and Laranjo Bay. This leads to a decrease of salinity in the lagoon. As the oceanic water starts to enter the lagoon during flood tide, salinity increases reaching its peak at high water when the central area of Ria de Aveiro is filled with ocean water. The brackish water at this time is pushed back into the upper sections of the channels. This pattern is repeated for each tidal cycle and brackish water is totally mixed with oceanic water when the freshwater input is small.

The variations of temperature are essentially dependent on tidal dynamics and on surface heating. However, there are also temperature variations due to the freshwater inflow. The temperature data measured at the mouth of the lagoon clearly reveals that there are two different temperature regimes in Ria de Aveiro: a semidiurnal regime related to the colder water input due to the tidal wave propagation along the shelf, and diurnal regime forced by the solar radiation heating effect. For a given surface heat flux $Q$, the change of temperature $(\delta T)$ in a time interval $\delta t$ is given by $\delta T=Q \delta t /\left(\rho C_{p} h\right)$ [15] (where $\rho$ is the density, $C_{p}$ is the specific heat of water and $h$ is the depth). Since $Q$ is a diurnal function, the change of temperature will also exhibit a strong diurnal component, especially in this summer season.

The maximum tempcratures inside the lagoon are reached at the far end of the channels, where the tidal effect is not so intense, in the afternoon on days when the sky is clear and the solar radiation heating effect is strong. Since in summer oceanic water is cooler than freshwater, the inflow of oceanic water into the lagoon leads to a slight lowering of water temperature. The difference between the inlet ocean temperature and the temperature at the far end of the channels can reach $7{ }^{\circ} \mathrm{C}$ (figure 9), these spatial differences being important in the net export of heat energy from the lagoon toward offshore waters.

Inside the lagoon the surface heating is also very important for the temperature distribution because normal levels of turbulence are sufficient to distribute the heat uniformly through the water column. According to the expression referred to above for the change of temperature $(\delta T)$, its value in a time interval $\delta t$ is larger the shalPower the water column $(h)$. Therefore the isotherms will follow the isobaths, with extreme values in the shallowest water at the far end of the channels. In these areas, as noted in section 4.3., the highest temperatures are found when the tidal currents are maximum if the highest daily insolation occurs during slack waters. This can be explained assuming that in these areas of the lagoon the tidal currents are weak, so a thermocline can be found close to the surface if the period of maximum insolation coincides with the period of slack waters figures 6 and 8). According to Nunes Vaz et al. [18], starting from a vertically mixed state even if the production of turbulence ceases abruptly there is a finite decay time-scale during which turbulent kinetic energy is still available within the water column to work against buoyancy forces. Tennekes and Lumley [25] give this decay time as the overturning time of the largest eddy, $h / u^{\prime}$, where $u$ ' is the rms turbulent velocity. Typically, $u$ ' is of the order of $0.01 \mathrm{~m} \mathrm{~s}^{-1}$ and so the turbulence decay time-scale at the far end of the channels in Ria de Aveiro is estimated as about $2 \mathrm{~min}$. Consequently it is reasonable to assume that the available turbulent kinetic energy falls to minimal 
levels during slack water periods. In such an environment and under the action of gravity and due to the surface heating, stratification is produced. When tidall currents start to increase, the presence of the thermocline inhibits vertical mixing, and only the highest values of the current produce enough turbulence to mix the water column and to distribute the heat uniformly to the bottom. In such cases the temperature of the water column increases and reaches its maximum value.

The low values of the salinity at the far end of Mira channel are unexpected since there is no direct river discharge. The small amount of freshwater inflow from the system of ponds and rivers does not seem enough to justify the extreme values that were found in this area. Perhaps they are a result of groundwater inflow or surface runoff input from the surrounding areas.

\subsection{Salinity and temperature structure}

Differences between surface and bottom salinity and temperature were found to be very small. Therefore, it can be postulated that in a dry season vertical gradients are negligible relative to longitudinal variations. However, after important rainfalls the vertical variation must be considered near the freshwater input locations. In the east zone of S. Jacinto channel, close to Laranjo bay, gravitational circulation maybe important even a long time after the rainfall, as the stratification found in the second survey period suggests (figure 8). In Ihavo channel the stratification will only be important for a small period after the rainfall, since the volume of freshwater of Boco river is small; the comparison between measured values during the first survey (not shown) and the second survey (figure 8) reveal a stratification pattern in the first situation and a homogeneous water column pattern in the second situation.

Until now Ria de Aveiro was usually considered a wellmixed lagoon. It is the competition between the various stratifying and mixing influences which determines the character of stratification in a lagoon. The main cause of stratification is the input of positive buoyancy by river freshwater [23]. Over limited regions the buoyancy flux due to rainfall, as well as the surface heating, are also important causes of stratification. Mechanical stirring by tidal stress on the bottom and wind stress at the surface produces mixing in the water column [18]. Negative buoyancy flux of increasing surface salinity and latent heat loss due to evaporation also have an effect in increasing mixing. The effect of mixing due to tidal currents was found to be dominant in almost all stations of Ria de Aveiro, especially when the river runoff was low. If the positive buoyancy due to freshwater input is sufficient to overcome mixing due to the maximum tidal currents, stratification will be established, especially in the channels under direct influence of river discharge. Comparing the results of the two surveys it is obvious that the degree of stratification depends on the magnitude of the freshwater flow. The buoyancy flux due to surface heating should also be considered as an important cause of stratification in this season, especially at the far end of the channels. The effect of mixing due to winds was found unimportant, since vertical salinity and temperature stratification persist even during the highest observed winds.

Using the obtained results, the classification of Ria de Aveiro by its stratification and by the characteristics of its salinity distribution, according to Pritchard [20] and Cameron and Pritchard [3], is not straightforward. The Mira channel can be easily classified as vertically homogeneous, but the S. Jacinto, Espinheiro and Ilhavo channels can be considered partially mixed or vertically homogeneous depending on the freshwater inflow volume.

\section{CONCLUSIONS}

Ria de Aveiro hydrology is essentially dominated by tidal forcing, responsible for a strong mixture of the water masses. The freshwater inflow, especially due to the Vouga and Antuã rivers, as well as the Boco river inflow after periods of strong precipitation, must also be considered in the circulation mechanisms. The solar radiation heating effect is important for the establishment of temperature patterns, especially in the shallow areas at the far end of the channels.

The tide at the mouth is semidiurnal, generating tidal currents strongly dependent on the local geometry. There is a clear tidal distortion inside the lagoon, especially at the extremities of the S. Jacinto and Mira channels. During its propagation the tidal wave amplitude decreases and the phase lag increases, so the tidal wave characteristics in Ria de Aveiro are those of a damped progressive wave.

The vertical salinity and temperature gradients in Ria de Aveiro can be neglected relative to the longitudinal gradients. The transverse gradients are in general small, but due to the freshwater input there are zones of lower salinity and higher temperature on the east side of S. Jacinto and at Espinheiro and Ilhavo channels. 
The longitudinal gradients are important; the lagoon has a water mass of high salinity and low temperature characteristic of the ocean water close to the mouth, which decrease and increase, respectively, upstream into the lagoon.

The Mira chanuel can be classified as a vertically homo-geneous estuary, while the S. Jacinto, Espinheiro and Ilhavo channcls are partially mixed or vertically homogeneous depending on the freshwater input.

\section{Acknowledgements}

The authors would like to thank Departamento de Biologia da Universidade de Aveiro for the use of its equipment, which made this work possible. They also thank Pascal Conan for help in the final revision of this study. This research was done within the framework of a $J N I C T / C N R S$ co-operation agreement and was supported by PRAXIS XXI through project EICOS.

\section{REFERENCES}

[1] A.C.P.C. Atlas Climatológico de Portugal Continental, Edição Preliminar, Serviço Meteorológico Nacional, Lisboa, 1974, $67 \mathrm{p}$.

[2] Bowden K.F., Physical Oceanography of Coastal Waters, Ellis Horwood Ltd, Chichester, 1983, 302 p.

[3] Cameron W.M., Pritchard D.W., Estuaries, in: Hill M.N. (Ed.), The Sea, John Wiley \& Sons, New York, 1963, pp. 306-324.

[4] Davies J.H., A morphogenetic approach to world shorelines, Z. Geomorphol. 8 (1964) 127-142.

[5] Cressie N.A.C., Statistics for Spatial Data, revised edition, John Wiley \& Sons, New York, 1993, 900 p.

[6] Denes T.A., Caffrey, J.M., Changes in seasonal water transport in a Louisiana estuary, Fourleaque bay, Louisiana, Estuaries II (1988) 184-190.

[7] Dias J.M., Granja A.P., Lopes J.F., Dekeyser I., Circulação Residual Provocada pela Acção do Vento na Ria de Aveiro, Proceedings of $1^{\circ}$ Simpósio de Meteorologia e Geofísica da APMG $/ 2^{\circ}$ Encontro Luso-Espanhol de Meteorologia (in press).

[8] Dias J.M., Lopes J.F., Dekeyser I., Numerical modelling of tidal fluxes and passive pollutants concentration in Ria de Aveiro, Portugal, in: Ferrante A.J., Brebbia C.A. (Eds.), Coast. Environ., Computational Mechanics Publications, Southampton, 1996, pp. 285-294.

[9] Dias J.M., Lopes J.F., Dekeyser I., Observações de hidrologia na Ria de Aveiro, Proc. Física 98, Maia (1998) 562-563.

[10] Doodson A.T., Warburg H.D., Admiralty Manuel of Tides, Hydrographic Department, Admiralty, London, 1941, 270 p.

[11] Dyer, K.R., Estuaries: A Physical Introduction, John Wiley \& Sons, New York, 1973, $140 \mathrm{p}$.

[12] Foreman H.G.G., Manual for tidal heights analysis and predictions, Pac. Mar. Sci. Rep., 77-10, Inst. Ocean Sci., Victoria, Canada (1977), $101 \mathrm{p}$.

[13] Hamming R., Digital Filters, Prentice-Hall, Inc. New Jersey, $1977,226 \mathrm{p}$.

[14] Kitheka J.U., Coastal tidally-driven circulation and the role of water exchange in the lirkage between tropical coastal ecosystems, Est. Coast. Shelf Sci. 45 (1997) 177-187.
[15] Lavín M.F., Godínez V.M., Alvarez L.G., Inverse-estuarine features of the Upper Gulf of California, Est. Coast. Shelf Sci. 47 (1998) 769-795.

[16] Lewis R., Dispersion in Estuaries and Coastal Waters, John Wiley \& Sons, Chichester, 1997, 312 p.

[17] Moreira M.H., Queiroga H., Machado M.M., Cunha M.R., Environmental gradients in a southern estuarine system: Ria de Aveiro, Portugal, Implication for soft bottom macrofauna colonization, Neth. J. Aquat. Ecol. 27 (2-4) (1993) 465-482.

[18] Nunes Vaz R., Lennon G., Samarasinghe J., The negative role of turbulence in estuarine mass transport, Est. Coast. Shelf Sci. 28 (1989) 361-377.

[19] Pedlosky J., Geophysical Fluid Dynamics. Springer-Verlag, New York, 1979, 624 p.

[20] Pritchard D.W., Estuarine circulation patterns, Proc. Amer. Soc. Civil Eng. 81, 717 (1955).

[21] Pritchard D.W., What is an estuary: physical viewpoint, in: Lauff G.E. (Ed.), Estuaries, American Association for the Advancement of Science, Publication 83, Washington, 1967, pp. 3-5.

[22] Queiroga H., Costlow J.D., Moreira M.H., Larval abundance patterns of Carcinus maenas (Decapoda, Brachyura) in Canal de Mira (Ria de Aveiro, Portugal), Mar. Ecol. Prog. Ser. 111 (1994) 63-72.

[23] Samarasinghe J.R.S., Lennon G.W., Hypersalinity, Flushing and Transient Salt-wedges in a Tidal Gulf - an Inverse Estuary, Est. Coast. Shelf Sci. 24 (1987) 483-498.

[24] Silva J.F., Circulação da água na Ria de Aveiro - contribuição para o estudo da qualidade da água, PhD Thesis, Univ. Aveiro, Portugal, 1994, 158 p.

[25] Tennekes H., Lumley J.L., A First Course in Turbulence, Cambridge, Massachusetts: MIT Press, 1972, $300 \mathrm{p}$.

[26] Unesco, Background papers and supporting data on the practical salinity scale 1978, Unesco Techn. Pap. Mar. Sci. 37 (1981) $144 \mathrm{p}$.

[27] Vicente C:M., Caracterização hidráulica e aluvionar da Ria de Aveiro, Utilização de modelos hidráulicos no estudo de problcmas da Ria, in: Jornadas da Ria de Avciro, Vol. III, Edição da Câmara Municipal de Aveiro, Aveiro, Portugal, 1985, pp. 41-58. 